\title{
THE UK NATIONAL THERMAL-HYDRAULICS FACILITY: MOTIVATIONS, DESIGN AND PLANNING STATUS
}

\author{
Dahlfors $\mathbf{M}^{1}$, Joannou $\mathbf{J}^{2}$, Brummitt $\mathrm{A}^{2}$, Rushton M J D ${ }^{1}$, Middleburgh S $\mathbf{C}^{1}$, and Lee W $\mathbf{E}^{1,3}$ \\ ${ }^{1}$ Nuclear Futures Institute \\ Bangor University, Bangor, Gwynedd LL57 2DG \\ ${ }^{2}$ UK Atomic Energy Authority \\ Culham Science Centre, Oxfordshire OX14 3DB \\ ${ }^{3}$ Institute for Security Science and Technology \\ Imperial College London, South Kensington Campus, London SW7 2AZ \\ m.dahlfors@bangor.ac.uk, jason.joannou@ukaea.uk
}

\begin{abstract}
A UK National Thermal-Hydraulics Facility (NTHF) dedicated to supporting new reactor and other relevant business is being developed, one of the purposes being to deliver on the government's carbon emission reduction commitments. The facility site is foreseen to be at Menai Science Park on the isle of Anglesey in North Wales, a region expected to see significant low carbon energy deployment in coming years. The UK NTHF is envisioned to cater for the needs of emerging nuclear in the UK - but also to serve as a hardware platform for international thermal-hydraulics research collaboration. Plans are to construct a platform capable of maintaining several test loops including support for the UK's on-going, conventional nuclear new build programme as well as Gen-IV systems and associated materials like molten salt and liquid metal coolant media. Motivations are given for NTHF expected capabilities and requirements, which form the basis for its current design and planning state.
\end{abstract}

KEYWORDS: Thermal-hydraulics, facility, testing, design

\section{INTRODUCTION}

In its June 2018 Nuclear Sector Deal, the UK Department for Business, Energy \& Industrial Strategy (BEIS) announced its partnership with the Welsh Government to develop a $£ 40$ million UK National Thermal-Hydraulics Facility (NTHF) in the North of Wales as an integral part of the $\mathrm{Nu}$ clear Innovation Programme (NIP) [1]. Outline design planning of the NTHF has been appointed to the UK Atomic Energy Authority (UKAEA). Geographical siting is more precisely foreseen to be the newly opened Menai Science Park (M-SParc) on Anglesey, a wholly owned subsidiary of Bangor University, see Fig. 1, who are growing their nuclear research expertise through the Nuclear Futures Institute (NFI) lead by Prof. Bill Lee and funded through the Sêr Cymru Welsh European Funding Office (WEFO) scheme. 
The aim is to boost the UK's nuclear new build programme as well as the development of Small Modular Reactor (SMR) and Advanced Modular Reactor (AMR) technology *, which implies that NTHF needs to provide a long-term platform that can cater for testing the Thermal-Hydraulic $(\mathrm{T} / \mathrm{H})$ properties of any reactor variant being developed for deployment in the UK - or for potential collaboration partners. While specific coolant technology selections are still to be determined, most likely testing capability should be prepared for Light Water Reactor (LWR) applications, i.e. BWR and PWR both for SMR and conventional plant implementation; Molten Salt Reactors (MSR); Fast Reactors (FR) cooled by sodium or lead; and High Temperature Reactors (HTR). Planning needs to incorporate technologies as they are being decided for implementation, including prioritisation when to start operating each coolant technology. A step-wise approach will help avoid commissioning and resourcing bottlenecks.

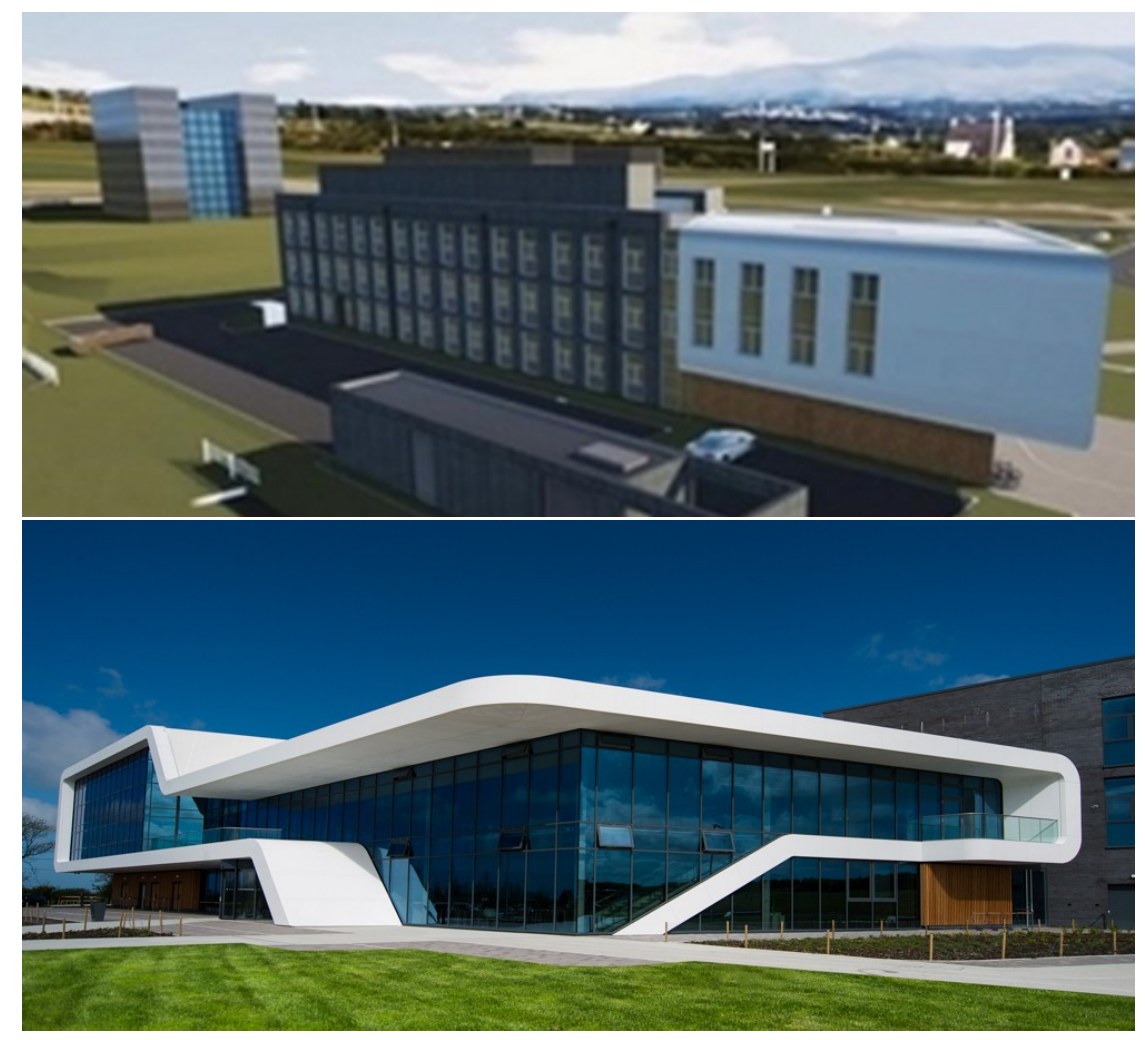

Figure 1: [Upper] Vision of M-SParc from West with NTHF building in background [Lower] Front view of M-SParc main building as it stands today

It should be emphasised that the present account of the NTHF design is presented without commitment or prejudice. The intention is not to convey any decisions regarding facility design, as its requirements and design specifications are subject to analysis and change. Now as throughout concept evolution, constructive input is welcomed and encouraged by developers. Requirements as set

${ }^{*}$ UK new nuclear terminology distinguishes between SMR and AMR; the distinction primarily being made between modular reactor systems as based on conventional reactor technology concepts that already have been deployed on grand scale (SMR), and those using more exotic technology which are expected to require more fundamental development (AMR). 
out in the paper do not necessarily reflect the standpoint of the UKAEA, NFI or any government actors, but primarily reflect the collective wishes and input of various participants and stakeholders throughout the development process, for elaboration refer to Section 2.1. Any proposals for the NTHF will be subject to final approval by the UK and Welsh Governments.

\section{FACILITY DEVELOPMENT}

The NTHF's development stakeholders are essentially industrial entities with an investment in the UK civil nuclear sector. Hence the scope of the facility is international already from the outset as a number of participating actors are multinational or based abroad. Central to NTHF specification development have been Frazer-Nash consultancy and the UKAEA, which have functioned as technical lead organisations through different stages of design progress. A total of at least 59 different organisations have contributed to requirements.

\subsection{Concept History}

The Nuclear Innovation and Research Advisory Board (NIRAB) was established in 2014 and in October 2015, the UK Government set aside $£ 250$ million for civil nuclear R\&D activities with the purpose to reinvigorate the UK nuclear industry [2]. In 2016, NIRAB announced a set of innovation and research recommendations, and one of these was the recommendation to develop a major new UK Nuclear Thermal-Hydraulic Test Facility.

The first specification of the NTHF was developed during NIP Phase 1 running from 2017 to 2019. Consultancy Frazer-Nash worked an initial leg under the contract awarded for Digital Nuclear Reactor Design - Thermal Hydraulics, and UKAEA took on a next leg of activity that culminated in the well-visited NTHF User Engagement Workshops held at M-SParc $13^{\text {th }}$ November 2018 (NUEW18), where stakeholders were given the opportunity to participate and influence future facility design development. The input derived from this event form the requirement basis for the design as presented in this text.

\subsection{Regional Setting and Nuclear Development Potential}

As part of NIP, the UK Government is working in partnership with the Welsh Government to develop the NTHF for North Wales, with the joint commitment of $£ 40$ million to the purpose [1]. With the investment comes the expectation that value be delivered for the UK and the region. Thus the NUEW18 identified value propositions across key themes for the facility, focusing on the local community as well as value for the UK in general. Within this context, it is worth noting proposed North Wales nuclear related ventures. The following sites and projects are being discussed:

1. Isle of Anglesey

- M-SParc - In connection with the construction of NTHF, planned to host a new Low Carbon Energy Centre of Excellence including central research labs, facilities and an innovation hub (funded in part through The North Wales Growth Deal)

- Wylfa-Claimed to be the best new nuclear site suited for major electricity generation plant in the UK 
- Coleg Menai - College for further education with apprentice, undergraduate and postgraduate training linking to local industry and community; Energy Centre at Llangefni campus

2. City of Bangor

- Main site for offices, teaching and research labs at Bangor University (through the Nuclear Futures Institute)

3. Trawsfynydd

- Proposed site for first deployment of SMR and AMR demonstration plants

- Potential proposal for research reactor aimed at medical isotope production, nuclear medicine and nuclear professional training

- Satellite low carbon energy centre of excellence linked to reactor type and regional hydro electric power and pump storage capability

The geographical locations of the above mentioned sites are mapped in Figure 2. It is clear that even partial scope implementation of the envisioned projects will have significant positive impact on the region by way of economic expansion, digitalisation/computing, skills and education, as well as construction activities over this area.
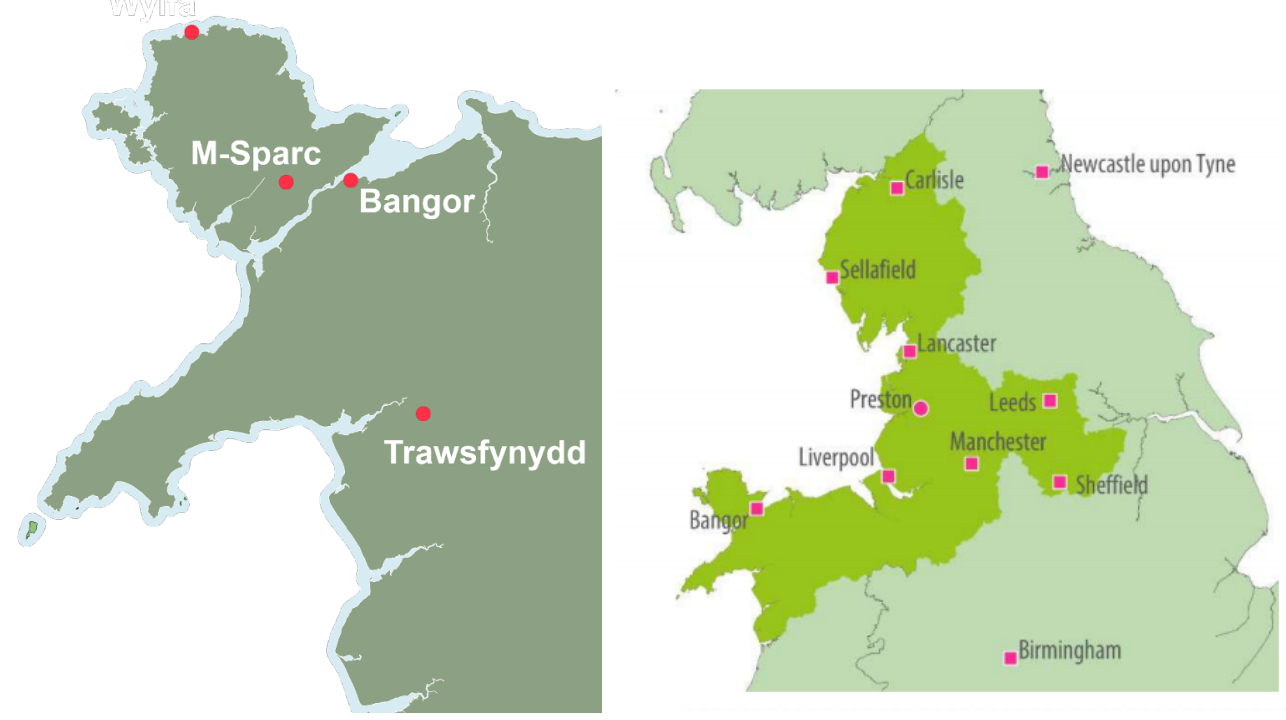

\section{Figure 2: [Left] North Wales Low Carbon Triangle: Bangor-Anglesey-Trawsfynydd [Right] Definition of the North West Nuclear Arc}

North Wales also constitutes the southernmost portion of the so-called North West Nuclear Arc (NWNA), cf. Figure 2. Other regions comprised are Liverpool and Sheffield city regions, Cheshire and Warrington, Cumbria, Greater Manchester and Lancashire. The North West Nuclear Arc Science and Innovation Audit states [3]:

The area encompasses a significant proportion of the UKs existing civil nuclear RD\&I, [...] and operational capability and there are sites available for large new nuclear deployments [...] the NWNA is unique in the UK in terms of Higher Education Institutes 
(HEIs), Tier 1 and 2 companies, and their supply chains, regulators, decommissioning and new build, as well as specialist facilities.

In other words, the siting of NTHF resonates well with other ventures underway both in North Wales and NWNA. Although the testing facility has a pronounced aim to service international needs, it is an important advantage that required industrial support as well as demand for services exist within comfortable geographical distance from the site.

\subsection{Operational Model}

A sustainable operational model will be needed to operate the NTHF. Once the investment budget is spent, a level of user-contributed financing will be required. Potential operational scenarios were investigated, and the need for the facility to offer a tailored contribution based service level to different users was identified. The design, and ramp up, of this service provision under these forms will be key during a component and system development operational phase, cf. Section 3.1.2.

In addition to facility functionality, the availability of transport links, cost of access (running costs), and the provision of an expertise service were identified. Further investigation is required regarding the cost of access and the potential for user funding.

\section{DESIGN}

NTHF aims to provide a platform for multi-purpose T/H testing over a range from conventional, deployment-ready reactor designs to concepts employing novel materials and coolant compositions. This leads to a variety of requirements and for flexibility to be designed into the facility.

Several loops of varying design need to be accommodated by the NTHF internal layout. These should be possible to deploy as modular entities to enable flexible schedules that can be adapted to funding availability. It is foreseen that major loops, i.e. those of large physical scale and those destined for the reactor concepts closest to market, will need to be designed integrally with NTHF buildings - but still in a way that permits reconfiguration for updates and variations. Some novel concepts employ primary coolant systems of smaller volumes from the outset, which should by itself cater for smaller scale $\mathrm{T} / \mathrm{H}$ loops for their purpose. Together with their longer time to market, this fact may allow for a more adaptive and successive deployment of their associated $\mathrm{T} / \mathrm{H}$ experiments.

Naturally, a harmonisation of the implementation pace needs to be conducted in collaboration with users, reactor developers and other stakeholders, but planning and allowing for sequential deployment of $\mathrm{T} / \mathrm{H}$ loop configurations will help avoid build bottlenecks and reduce risk for delays. During the NUEW18, requests were put forward that small scale testing for alternative coolants be introduced earlier than originally recommended, which is also observed in Section 4. However, the project prioritisation process must consider that near market concepts based on proven technology will require access to NTHF services imminently. 


\subsection{Facility Capability}

Before the NUEW18, the high-level reactor categories relevant for NTHF development had been identified. Bearing in mind that more investigation may be needed to determine actual demand, the following reactor concepts were represented or discussed during workshops:

\section{Light Water Reactor (LWR)}

- Pressurised Water Reactor (PWR)

- Boiling Water Reactor (BWR)

\section{Liquid Metal Reactor (LMR)}

- Lead-cooled Fast Reactor (LFR)

- Sodium-cooled Fast Reactor (SFR)

\section{Molten Salt Reactor (MSR)}

\section{High Temperature Gas Reactor (HTGR)}

Outside these, it could be explored if there are other applications where the services of NTHF could be desired. T/H research aimed at renewable energy, energy storage or non-reactor nuclear material processes are examples of applications where user interest and good facility suitability could be found.

As the NTHF will need to implement a number of different $\mathrm{T} / \mathrm{H}$ testing loops, its design must consider whether experiments may need to run simultaneously and to what degree sharing of components will be possible. Co-generation and process water heat conservation schemes are to be considered where applicable with the aim to develop economically viable, pragmatic energy efficiency and storage solutions for the wider society in the long term. Furthermore, on-site capacity has to be provided with respect to design and rig building facilities, including areas for instrumentation development, maintenance and assembly. Computing and operation controls infrastructure also need to be considered in NTHF plans.

\subsubsection{Pressurisation and Convection Modes}

It is expected that virtually all loops to be deployed will need to provide means for operation modes with forced circulation as well as natural convection, while some loops will also require pressurisation and the possibility to simulate flow reversal. The variation in testing requirements becomes apparent if we consider the case of molten salt or liquid metal $\mathrm{T} / \mathrm{H}$, where a pump needs to circulate significant coolant mass but under low pressure in line with the conditions prevailing in the system being emulated by the loop. At the other end of the spectrum we find LWR concepts, of which some novel SMR are able to employ natural circulation (no need for pumping), but where significant pressurisation is required. Thus, NTHF generally should be designed for versatile loop capabilities when so viable to allow for significant system parameter variations in each coolant testing category, as these can vary considerably depending on the specific concept targeted. 
It can be generally established that natural convection as well as low pressure constitute testing conditions that always will be important for transient ${ }^{\dagger}$ or accident $\mathrm{T} / \mathrm{H}$ state emulation vital to safety analysis. For academic and Computational Fluid Dynamics (CFD) validation purposes, these conditions are also of high interest.

\subsubsection{Projected Facility Uses and Operational Phases}

Within each coolant/fluid testing category, the following core uses or operational phases have been predicted:

1. Code validation (validation of digital twins) \& underpinning safety case

2. Digital/physical hybrid models
3. Component/System Development

4. Equipment qualification

5. Fleet support

A number of supplemental (non-core) but important testing fields have been identified. These include chemistry and corrosion (environmentally assisted degradation including crud), fluid and gas monitoring instrumentation, as well as control logic development. In the field of computation, data acquisition, processing and imaging system development form an integral part of experiment design. Rig operation will require real time analysis solutions that may find economic or safety enhancing application in nuclear industrial process.

\subsection{Measurement and Instrumentation}

Control and Instrumentation (C\&I) to support state-of-the-art measurement presuppose instrumentation employing techniques based on

- Gamma/x-ray based computed tomography

- Laser Particle Image Velocimetry (PIV)
- Laser Doppler Anemometry (LDA)

- Acoustics

NIP Phase 1 resulted in a recommendation to include 3D measurements with a strong focus on X-Ray CT techniques along with PIV, LDA and acoustic measurements. Key measurements for non water experiments were also identified, including the need to develop a measurement strategy for measuring the temperature profile across high temperature gas reactor cores. The ability to use real time control for digital twinning during experiments would become of interest, but may not be required on day one of the NTHF.

\section{REACTOR TYPE SPECIFIC REQUIREMENTS}

In the formulation of the reactor type specific requirements it has been assumed that the most complex and voluminous geometry allowed in any rig is a full size fuel bundle, possibly including

\footnotetext{
${ }^{\dagger}$ Note that complete transient course emulation requires departure from a forced circulation and pressurised state, with passage through transitory conditions to a final state where natural convection and possibly lower pressures prevail.
} 
inlet (partial) inlet orificing features. For some applications, it is likely that simplified geometries could yield satisfactory results. For example, single-phase operation of fluids with reasonable heat transfer properties (the case for LMR and MSR) should allow considerable simplifications in comparison with the voided conditions encountered in the study of Departure from Nucleate Boiling (DNB) or dry-out in the case of LWR.

Due to financial, resource and logistic constraints as discussed in Section 3, it is likely not realistic or even desirable to construct a complete set of NTHF loops by the initial operation date. It is therefore observed that effort needs to be spent on test loop prioritisation for day one and the planning how capabilities thereafter could be added sequentially at greatest possible pace.

\subsection{Light Water Reactors}

In general LWR testing is required to support both natural and forced convection under pressurised conditions. For PWR up to 180 bar and for BWR around 85 bar would be required for adequate pressure transient emulation. If nominal pressures are suffice, then 160 bar suffices for PWR and 72 bar for BWR. Flow rates per bundle in PWR do not typically exceed $100 \mathrm{~kg} / \mathrm{s}$, in BWR max is $20 \mathrm{~kg} / \mathrm{s}$.

A $12 \mathrm{~m}$ high large scale natural circulation water based test loop capable of reaching prototypical reactor conditions has been suggested, but it remains to be explored whether its application scope motivates cost. Such a rig would be useful to explore LWR accident final conditions but has less relevance to normal operation or design basis events. If the set-up were possible to pressurise and run with forced flow, some unique tests could be performed, particularly in the case of BWR. A key component for the realisation of such a rig would be commercial participation or requirements driven by regulation.

The above mentioned large scale rig is not designed for application to a nominal operation fuel bundle testing perspective like in the case of DNB/dry-out focused measurements. It may not be feasible to serve both PWR and BWR even with a smaller fuel performance oriented rig; partly due to the rather different fuel geometries, and partly because PWR requires high pressures that are unnecessary in the BWR case. Furthermore, BWR in its turn imposes operation requirements unnecessary in the PWR case, i.e. the need for full-on two-phase flow with a strong void gradient over the bundle resulting in a dominant steam component (up to $80 \%$ void) at the top of the bundle. However, significant system sharing opportunities still exist in pump, pressurisation, instrumentation and auxiliary equipment and these are to be explored. Fuel testing sections do share some characteristics, e.g., a $4 \mathrm{~m}$ tall set-up employing forced convection with $\geq 15 \mathrm{MWe}$ input power could work as an appropriately dimensioned specification of a partial fuel bundle platform.

Since the PWR represents the most dominant reactor design, some potent $\mathrm{T} / \mathrm{H}$ testing facilities already exist around the world. However, many of these have pre-existing commercial ties and in the UK there is no major facility. With a PWR technology based SMR concept already being developed by a Rolls-Royce-led UK consortium [4], it is clear that domestic access to generalised, state-of-the-art $\mathrm{T} / \mathrm{H}$ testing has the potential to boost development and optimisation efforts. Largescale PWR stations already exist or are being built in the country, and also here long-term benefits can be won. In the case of PWR applications, it will be vital for designers to identify interest amongst UK industry representatives and collaboratively develop the specification for a test loop 
that is operational from Day 1.

Natural challenges with a PWR loop are the high system pressure required together with relatively large radial fuel dimensions. The latter can be mitigated by partial bundle implementation without too much loss of information thanks to benign PWR standard conditions with homogeneous lattice and scarce control rod insertion. In a future with more demanding PWR operational modes, e.g., grid follow with significant control rod insertion like in BWR, bespoke measurements could be needed to support operations optimisation, improve thermal margins and thus enhance safety.

In the case of LWR, several opportunities for novel work exist. Among these are:

- Development of non-proprietary dry-out and void correlations for use in non-vendor codes nominal operation fuel bundle/channel testing capability is needed.

- Potential improvement of CFD two-phase predictions and boiling; particularly important for BWR, but also applies to PWR in respects of transient calculations and sub-cooled boiling.

- Refinement of reduced-order DNB/dry-out and void prediction.

- Supporting the development of Hitachi's Resource-renewable Boiling Water Reactor (RBWR), which features a tightly-packed, hexagonal lattice and high void fractions [5] - RBWR fuel will require entirely new dry-out and void correlations.

- BWR Thermal-Hydraulic instability emulation - exploration of core-wide and regional instability behaviour at low circulation flow/high power in dedicated large-scale set-up; channel instability could be probed via regular fuel bundle/channel measurements.

- Testing of fuel support orifice throttling and support-beam induced cross-flow conditions below the core in certain BWR types.

In general, the boiling process is of high interest, as fundamental description and modelling still pose challenges. An appropriately instrumented and analysed LWR loop, particularly one with boiling capability, could provide valuable data for validation of CFD methods and models applicable to two-phase flow and boiling.

\subsection{Liquid Metal Reactors}

While LMR do not represent truly novel technology, their modern implementation is likely to employ a number of first-of-a-kind (FOAK) features. Testing will therefore be required to support licensing of components and subassemblies, and the development of new materials.

An integral facility with electrically heated fuel assemblies has been proposed with the following characteristics:

- Integral vessel, electrically heated fuel assemblies

- 1-2 Pumps, 1-2 Heat exchangers

- 100-200bar secondary side pressure (primary side at low pressure)

- $10 \mathrm{MW}$ power for testing at week scale, $1 \mathrm{MW}$ power at year scale

- Rig height 4-5m, 2m vessel diameter, building 10x10x10m 
A small scale rig at $100 \mathrm{~kW}$ with 100-200 bar (secondary) has also been suggested for purposes of destruction testing, long term erosion/corrosion, and volatile retention.

Parameters to measure in each set-up comprise

- Flow in channel

- Cladding temperature

- Inlet/outlet temperatures

- Pressure Drop over core
- Oxygen sensors

- Level meter

- Viscosity

A request was made at NUEW18 that sodium and lead coolant variants (or surrogate media at similar viscosity) be accommodated in a small scale rig set-up from an early operational stage.

\subsection{Molten Salt Reactors}

MSR technology requires $\mathrm{T} / \mathrm{H}$ testing to support:

- Identification of optimal molten salt loop • Component \& material qualification (flow sheeting)

- Material properties of various molten salts including contaminants

- Development of materials for moderators and components

- Full scale tests for training, faults and control systems

- Increased understanding of salt handling and salt preparation

When constructing a rig, it needs to be explored whether different salts need be tested in different loops, or if there are ways to have different salts in the same loop. It may be practical to employ a representative, generic salt for $\mathrm{T} / \mathrm{H}$ specific testing, while lab scale or small scale loop testing is done separately to determine specific salt material properties.

Suitable techniques to employ in connection with MSR T/H property include standard temperature measurements with thermocouples in addition to those based on ultrasonic Doppler and velocimetry. Important properties to probe comprise spatial temperature resolution as well as melting and solidification behaviour of salts. It is to be noted that a number of coolant and fuel matrix salts of varying relative compositions need to be tested to arrive at optimal choices.

\subsection{High Temperature Gas-Cooled Reactors}

Testing that is required to support HTGR will comprise:

- Core to case/environment temperature profile

- Materials testing at high temperatures $\left(700{ }^{\circ} \mathrm{C}, 1000{ }^{\circ} \mathrm{C}\right.$ and above)

- Cycling induced fatigue

- Understanding temperature profiles for safety case approval
- Pressure drop across a graphite core

- Flow resistance tests

- Leak paths

- Effect of dimensional tolerance on flow resistance 
A rig that is representative of a core with ability to change fuel rod configurations would be needed to appropriately emulate T/H conditions. Sensor development will be required to measure inside the resulting set-up; the central parameters are in-core temperature and pressure profile. Different coolant types will need to be tested, a feature that may be needed early on in development.

\section{CONCLUSIONS}

A versatile National Thermal-Hydraulics Facility is being planned in the UK for testing of the $\mathrm{T} / \mathrm{H}$ properties relating to reactor concepts ranging from conventional, near-deployment systems to novel ones, employing first-of-a-kind coolants, materials and sensors. The facility is foreseen to be sited at the Menai Science Park on the isle of Anglesey in North Wales, a region expected to see significant low carbon energy development and deployment in coming years.

The facility is envisioned to cater for the needs of emerging nuclear technologies in the UK - but also to serve as a hardware platform for international thermal-hydraulics research collaboration. Plans are to produce a design capable of maintaining several test loops including such that support the UK's on-going, conventional nuclear new build programme as well as Gen-IV systems and associated materials, including molten salt and liquid metal coolants. The basis for its current design and planning state has been described by way of expected capabilities in generic terms and as dependent of reactor type specific requirements.

\section{ACKNOWLEDGEMENTS}

The latest design iteration of the NTHF is largely based on the outcomes of the November 2018 NTHF User Engagement Workshops at M-SParc, and the authors are therefore much indebted to all contributors sharing their experience and requirements during that event. Many thanks also go to Dean Paul Spencer, College of Environmental Sciences and Engineering, Bangor University, for his support that has facilitated the production of this article.

\section{REFERENCES}

[1] Department for Business, Energy \& Industrial Strategy, Nuclear Sector Deal - Policy paper, HM Government, London, United Kingdom (2018). https://www.gov.uk/government/publications/nuclear-sector-deal/nuclearsector-deal

[2] Nuclear Innovation and Research Advisory Board (NIRAB), The UK Civil Nuclear R\&D Landscape Survey, February 2017, NIRAB-123-4, United Kingdom (2017). http://www.nirab.org.uk/media/10671/nirab-123-4.pdf

[3] Department for Business, Energy \& Industrial Strategy, The North West Nuclear Arc Science and Innovation Audit, HM Government, London, United Kingdom (2018).

[4] Rolls-Royce, UK SMR: A National Endeavour, Rolls-Royce plc, United Kingdom (2017). https://www.rolls-royce.com/ /media/Files/R/Rolls-Royce/documents/customers/nuclear/ a-national-endeavour.pdf

[5] T. Hino, T. Nagayoshi, T. Mitsuyasu, M. Ohtsuka, K. Moriya, Development of RBWR for Recycling and Transmutation of Transuranium Elements - Overview and core concept, Societe Francaise d'Energie Nucleaire (SFEN), Paris, France (2015). 